\title{
Effectiveness of Forehand Technical Training Model toward Increased the Ability of Playing Tennis on the Training
}

\author{
Nurkadri \\ Faculty of Sport and Science, Medan State University
}

\begin{abstract}
This study was referring to the level of ability students' playing in Sport Department of Faculty Sport and Science UNIMED was low. It proved by the result of observations which conducted by the researcher showed that the error rate of forehand was $65 \%$. It caused by the basic training model forehand-oriented techniques which used by lecturers are using conventional models and unstructured program. The results of the interviews also showed that the basic tennis practice model book owned by lecturers is one of the obstacles, confirmed by the distribution of need analysis questionnaire. So, innovation of the basic technical training model forehand tennis courts was needed for students who take tennis court courses. The novelty of this research was on the basic technique model of forehand tennis field effective towards the improvement of basic technique ability of students of FIK UNUMED. The specific targets to be achieved were testing the effectiveness of the basic tennis forehand exercise technique model and producing a basic forehand technique of training model that effectively improves students' technical skills. This study was conducting by quantitative approach with experimental form. The research design was randomized control group by pretest-posttest. It can be concluded that there were an increase of the effect of basic forehand technique training and conventional technique training on the basic technique capability of forehand in the students of FIK Department UNIMED.
\end{abstract}

Keywords: Forehand Model and Coaching Department

\section{Introduction}

\section{Background of the Research}

Every year, student of Universitas Negeri Medan (UNIMED) regularly participate in the tournament of three cognate countries namely Indonesia, Malaysia and Thailand. The game is called IMT-GT which participants are Universities in North of Indonesia, North of Malysia and North of Thailand. Unimed is regularly send their students to participate in this event, therefore student of FIK (Fakultas ilmu Keolahragaan) motivated to compete and mastery of tennis and could become as representative of unimed in the tournament. This is one of them motivates FIK UNIMED students to compete to master this tennis sports branch and represent the University in the game. In the Coach Department of UNIMED, tennis is a compulsory course that must be taken as one of requirement for graduation.

From the observations in several months which conducted by researcher, it shows basic tennis technique exercises only focused on how to hit a ball with a racket and swing the racket after that continue with game regardless the condition to supporting approaches of techniques basic tennis are good and correct. Moreover, the exercise applied only with the memory of lecturer and teaching plans based on lecturer experience while being an athlete. The worse matter is the basic engineering skill exercises do not have a clear exercise program. This certainly gives a bad impact on the ability of tennis students to create a reliable student.

As per questionnaire distribution of requirement analysis to the students who was follow the course mentioned above, there was $40.5 \%$ of tennis students do not know the model of exercise other than that given by the lecturer, $5.8 \%$ of students never know the basic tennis practice technique model, and $50.50 \%$ of students strongly agreed to be given a model of exercise approach and basic tennis techniques and
$3.20 \%$ of students said they did not agree to be given a model of approach to playing exercises and basic tennis techniques.

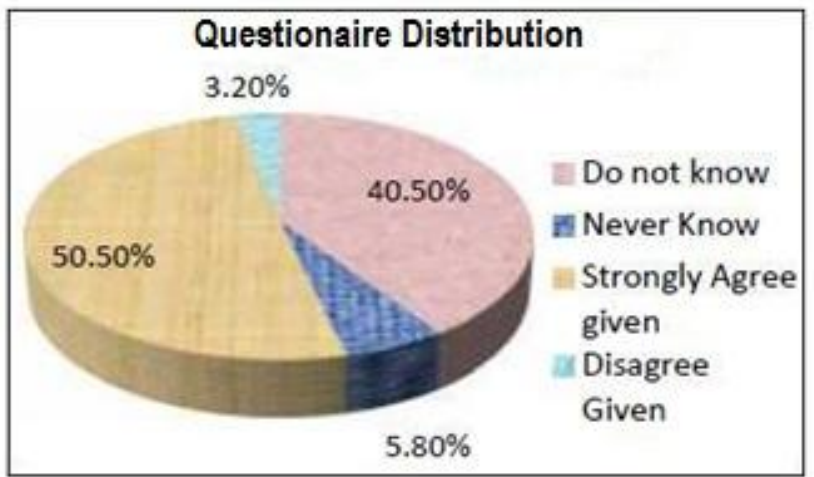

Picture 1: Spread of Questionaire Analysis of Requirement of the Players which follow the Course

The result of the analysis related to the basic tennis technique model that will be developed based on requirement analysis and the theoretical review examined is the basic tennis forehand exercise technique combined with the playing approach exercise. The training processes have three stages: mental stage, practice stage, and automatic stage. The process in each exercise provides an explanation of how these exercise to do, demonstrating the model of the exercise, the player practicing it with lecturer supervision, and correcting the mistakes made. The basic tennis practice model forehand tennis certainly need to be tested effectiveness to increase the basic technique skills of student tennis in the Department of FIK UNIMED. The effectiveness test is a series of the development of basic technique model forehand tennis to find out how much the effectiveness of basic technique forehand tennis training model on the basic technique of playing tennis students in the Department of FIK UNIMED.

Volume 6 Issue 7, July 2017

www.ijsr.net 


\section{International Journal of Science and Research (IJSR) \\ ISSN (Online): 2319-7064}

Index Copernicus Value (2015): 78.96 | Impact Factor (2015): 6.391

\section{Research Novelty}

The developed model is a combination of playing approach exercises that support basic tennis forehand exercise techniques. This combination is a model that is effective and efficient due to in the exercises; the students get the basic biometric abilities of the punch and blow technique. The training model that will be developed will be tailored to improve the ability of field tennis students to play well.

The research on basic tennis forehand exercise model with playing approach is a new research, considering there is no basic technique training model that combines basic technique and simultaneous playing approach in a series of motion.

\section{Research purposes}

The objectives of the research focused on testing the effectiveness of the model basic tennis forehand exercise model which was a series in the development of the basic tennis punch training model. Specifically, the purpose of this research as follows:

1) Produce a basic drill model forehand for the tennis.

2) Produce a product of basic exercise model forehand tennis.

3) Testing the effectiveness of the basic tennis forehand exercise model.

4) Improving students' ability to playing tennis.

\section{Urgency Research}

The virtue of this research is the testing of the effectiveness of the basic tennis forehand exercise model to meet the needs skills of tennis students in the FIK UNIMED's Department of FIK in playing abilities and the biometric components that support them. Based on result of requirement analysis indicates that student's play ability to was not good. Therefore, it was necessary to have a model of exercise enhance capability of playing tennis and biometric components that support basic blow technique. This forehand training model will be conducted with many variations adjusted to the field and students condition. In addition, in the process of training, students will perform good and correct playing techniques.

\section{Target Findings}

The target of the findings in this research is the effectiveness of basic forehand training models which develop a good and correct playing technique and the bio motor components that support them. This basic forehand exercise model also combines drill and games methods in the training phase. The findings of this research were a basic exercise model forehand tennis with emphasis techniques and supporting approaches are wrapped with drill and games variations.

\section{Literature Studies and Hypotheses Development}

\subsection{Tennis Concept}

According to Yudoprasetyo argues that the basic principle in tennis is not just hitting the ball over the net and dropping it into the opponent's playing field, but in hitting the ball is made to do a good punch that can direct the ball and can place the ball carefully in a desired place in order to get result can be difficult for the opponent to return it, so that the opponent blows off the field or is concerned on the net. Thus it will get the value of the result of a wrong blow done, because any mistake in the blow resulted in the acquisition of value for the opponent.

Jones \& Angela Buxton pointed out in his book that basic skills in game tennis are divided into three categories, including: (1), service (2) groundstrokes (forehand and backhand), (3) volley basic tennis. For each point start with: Service: the basic way this movement is 'toss' towards the ball. Once the ball is played, the rally goes with: groundstroke. This is the blow you made after the ball hit the ground once. A blow done without waiting when touching the ground is called: Volley. The basic way to volley is to hit the ball with a racket surface. So the basic technique has a vital role and must be owned by all tennis players. Therefore, the basic technique skills of tennis should be gained more attention in training. Researcher is forward the basic technique of punch with a model development to improving the technique of tennis players in the province North of Sumatra.

\subsection{Forehand Model Concept}

Thompson Said that exercises is a systematic process with the aim of improving the athlete's physical fitness by doing certain activities. Further Understanding exercises derived from the word exercise is the main tool in the daily exercise process to improve the quality of the function of the human organs system, thereby facilitating the sportsman in perfecting his motion. Understanding the exercise derived from the word training is the application of a plan to improve the ability of exercise that contains material theory and practice, methods, and rules of implementation in accordance with the goals and objectives to be achieved.

Explanation above explain that the purpose of the exercise is to improve body fitness and a plan to improve the ability in which there is material theory and practice, methods and rules of implementation, the author make a basic tennis exercise model that uses the method of playing approach to train basic tennis court. Seeing from what the goal of the exercise is to improve the ability to play tennis.

Games are a common phenomenon, both in the animal and human worlds, such as the environment of learners, youth, and adults. The game is a self-chosen activity without any element of coercion, without being urged by a sense of responsibility. The game has no specific purpose. The goal of the game is the game itself and can be achieved at play time. Playing is not the same as working. Work has a further goal and it will achieve once the job is done. Learners like to play because inside them there is an inner urge and encouragement to develop themselves. Many scientists are interested in researching the game because they are aware of the importance of game play in development.

While Docket and Fleer argue that play is a necessity for children, because through playing the child will gain knowledge that can develop his ability. Playing is a distinctive activity and very different from other activities 


\section{International Journal of Science and Research (IJSR) \\ ISSN (Online): 2319-7064}

Index Copernicus Value (2015): 78.96 | Impact Factor (2015): 6.391

such as learning and work are always done in order to achieve a final result. From the above description can be concluded basic tennis exercise is the process of interaction between sports field tennis with players and training resources. Developed this exercise model based on; Technical training and skill practice and followed by a play approach in the form of small field games with the same number of players (small-sides games). As a manifestation of the characteristics of novice players are dynamic, active and adaptive.

The combination of training methods justified by Ria Lumintuarso which shows in practice, both methods of exercise are used in combination. Consideration of combining the exercise method is based on the technique that is intended to master the form of skill motion that is standard. While the method of play approach is destined for problem solving in real game situations aimed at mastery of basic techniques better in the game of tennis.

\subsection{Concept Model of Engineering Exercise}

In doing bompa technique exercises it is not recommended for the purpose of the elite athletic technique, because of their technique may be beophysiologically not biomechanical requirements.

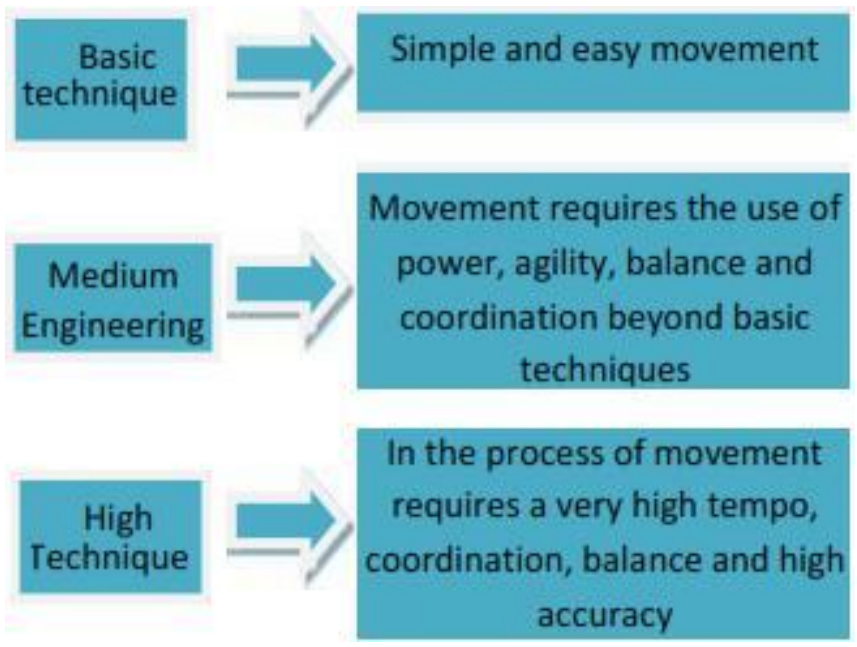

Figure of engineering classification

Based on the classification above, it can be understood that in doing every engineering exercises it should through several stages from the easy to the high level, referring to those theory this research will doing such a way that in basic training of tennis field will use the stage as above

According to Rusdianti \& Seto Budiwanto engineering exercises must go through several processes that can be seen in the chart on the next page:

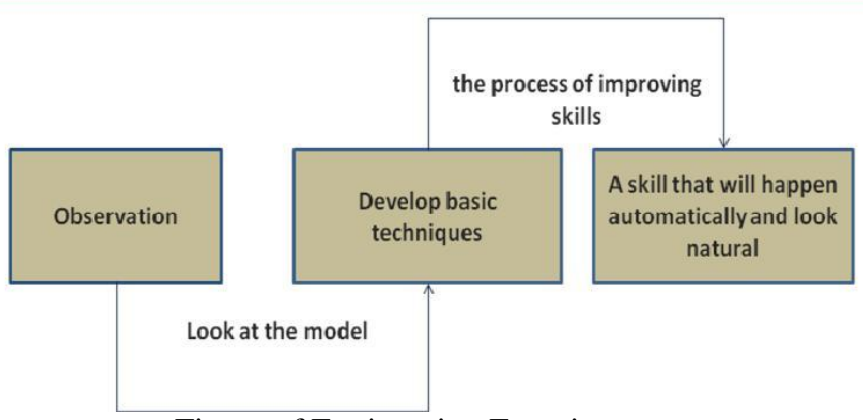

Figure of Engineering Exercise stage

Meanwhile according to Rainer Martens there are three stages in doing engineering exercises, they are:

a) Mental stage : mental stage has a meaning that in doing engineering exercise on the first stage must be careful and Should not be loaded until overload, because in this phase is the introduction phase of the technique.

b) Practice Stage: practice stage has a meaning on Emphasis on quality exercises to improve the technique.

c) Automatic Stage : Automatic stage has a meaning more controlled techniques occur automatically, Certainly in this case will free up the mental capacity of the stage and focus more on the more important elements of the technique to show great performance

The technique theory above is an engineering exercise in general that is used in all sports, so that the need for a more in-depth study of technical exercises specialized field of field tennis field so that later in drafting the basic tennis model exercise model can be justified.

It means that the technique training methodology shows starting from the basic stages of technical training and continuing skill training or playful situations then technical training is continued in the form of play situations with the same number of players. Expands the model of this exercise based on: technical practice and skill practice and continue by Small game field form with the same number of players (small-sides games).The term fundamental, game related and game situation. Understanding that every techniques train begin with basic engineering exercise and continued in the form of simplified play then proceed into play situations.

\section{Research Hypothesis}

Based on the explanation above, it can be arranged hypotheses in this study was the basic technique of forehand tennis field technique effective to improve the ability of playing field tennis of FIK UNIMED students.

\section{Research Methods}

\section{Approach and Type of Research}

This research was an experiment effectiveness test of basic technique forehand tennis through playing approach. Research approach in this research was quantitative which was as a part of research and development (R \& D) basic technique model forehand tennis field in step six that was big group trial. This type of research is experimental research with basic technique model forehand tennis field as treatment or treatment in experimental research. The design

Volume 6 Issue 7, July 2017

www.ijsr.net 


\section{International Journal of Science and Research (IJSR) \\ ISSN (Online): 2319-7064}

Index Copernicus Value (2015): 78.96 | Impact Factor (2015): 6.391

of this study was randomized control group pretest-posttest which can be described as follows:

\begin{tabular}{|c|c|c|c|c|}
\hline $\begin{array}{c}\text { Sampling } \\
\text { Technique }\end{array}$ & Group & Pretest & Treatment & Posttest \\
\hline \multirow{2}{*}{ Random } & $\begin{array}{c}\text { Forehand } \\
\text { basic } \\
\text { technique } \\
\text { training } \\
\text { model }\end{array}$ & $\mathrm{P} 01$ & $\mathrm{X} 1$ & $\mathrm{P} 1$ \\
\cline { 2 - 5 } & Control & $\mathrm{P} 02$ & - & $\mathrm{P} 2$ \\
\hline
\end{tabular}

Note;

P01: Pre-test experimental group 1

P02: Pre-test control group

$\mathrm{X} 1$ : Treatment model of basic forehand technique training developed

- : Treatment of Conventional Workouts

P1: Post-test experimental group 1

P2: Post-test control group

\section{Population and Sample Research}

The population of this research was all of field tennis students who take field tennis courses in odd semesters. Subject of this research were 80 students of coaching Department FIK Unimed.

\section{Time and Place of Study}

This research was conducted on April-September 2017 with a 8 times of meeting. The place of the research was in the Tennis Field of FIK UNIMED who were designated as research samples.

\section{Research Instruments}

The research instrument was used Hewit tennis field test battery consisting of forehand test. The test items have been tested for validity and reliability. The forehand test items get a validity score of $0.74(>0.36)$. Based on that value then the test battery Hewit tennis field declared valid. The reliability value of the test battery Hewit tennis field is $0.63(>0.36)$, then it can be declared reliable.

\section{Data analysis technique}

Data of pre-test and post-test on experimental group and control group were analyzed using SPSS 17.0 for windows with the following analysis according to Sugiono:

\section{1) Test Prerequisite Analysis}

Here were the steps taken by the researcher when test prerequisite analysis: a. Normality test in this research was used to test the data obtained normal distribution, done by Kolmogorove-Semirnov test with $5 \%$ significance level. B. Homogeneity test in this research is used to test the data obtained whether homogeneous or not. Using levenes's test

\section{2) Hypothesis Statistics Test}

To know the difference of treatment effect on the dependent variable of Punch results before and after treatment of each group used Paired t-test.

\section{Result and Discussion}

Based on the results of experimental in small groups, experimental in large groups and the result of effectiveness test it can be seen that the model of basic training techniques forehand tennis field students who have developed in this study was considered eligible also worthy of use and integrated in the exercise program, especially on Basic forehand technical training materials for FIK UNIMED students. This research also shows differences in the results of basic engineering tests after being given treatment in the form of applying the basic exercise model forehand field tennis on students. Looking at the average value between before and after treatment, there was an increase in the average value of forehand basic technique test result that was; (1) basic technique forehand of ability increase of 8,55 that is from pretest equal to 14,72 and posttest equal to 23,27 .

\section{1) Basic Technique Test Results of Forehand}

\begin{tabular}{|c|c|c|c|c|c|c|}
\hline No & $\begin{array}{l}\text { Test } \\
\text { Results }\end{array}$ & Category & Students & Percentage & Total & Percentage \\
\hline \multirow{5}{*}{1.} & \multirow{5}{*}{ Pretest } & Very well & 5 & $12,5 \%$ & 5 & $12.5 \%$ \\
\hline & & Good & 17 & $42,5 \%$ & 17 & $42,5 \%$ \\
\hline & & Medium & 15 & $37.5 \%$ & 15 & $37.5 \%$ \\
\hline & & Less & 2 & $5 \%$ & 2 & $5 \%$ \\
\hline & & $\begin{array}{l}\text { Less } \\
\text { Once }\end{array}$ & 1 & $2,5 \%$ & 1 & $2,5 \%$ \\
\hline \multirow{5}{*}{2.} & \multirow{5}{*}{ Posttest } & Very well & 28 & $70 \%$ & 28 & $70 \%$ \\
\hline & & Good & 7 & $17,5 \%$ & 7 & $17,5 \%$ \\
\hline & & Medium & 5 & $12,5 \%$ & 5 & $12.5 \%$ \\
\hline & & Less & 0 & $0 \%$ & 0 & $0 \%$ \\
\hline & & $\begin{array}{l}\text { Less } \\
\text { Once }\end{array}$ & 0 & $0 \%$ & 0 & $0 \%$ \\
\hline
\end{tabular}

From the table above, it can be seen that there were 28 students $(70 \%)$ increase in the number of students who fall into the category of forehand basic technique "very good" from the previous 5 students $12.5 \%$ were included in the "excellent" category, The basic technique forehand tennis field training model than 23 students $(57.5 \%)$ increased. In the basic "good" forehand technique category there was a significant decrease from the previous 17 students $(42.5 \%)$, after the exercise using the basic technique of forehand tennis field to 7 students (17.5\%), there was a decrease of 10 students $25 \%$ ) in the "good" category. Then on the basic technique category forehand "moderate" there was a significant decrease from the previous 15 students (37.5\%), after the exercise using the basic technique of forehand tennis field into 5 students $(12.5 \%)$, there was a decline in 10 students $(25 \%)$ in the list of "moderate" categories.

And then there were no more students who fall into the category of basic forehand "less" and "very less" techniques than the previous forehand basic "less" 2 students, and the basic forehand "very less" technical category is one student. The result of comparison of the basic forehand technique test before and after the exercise is done by using the Forehand Basic Technique Exercise Model the tennis field On Students Based Approach to Play can be seen in the following graph. 


\section{International Journal of Science and Research (IJSR) \\ ISSN (Online): 2319-7064}

Index Copernicus Value (2015): 78.96 | Impact Factor (2015): 6.391

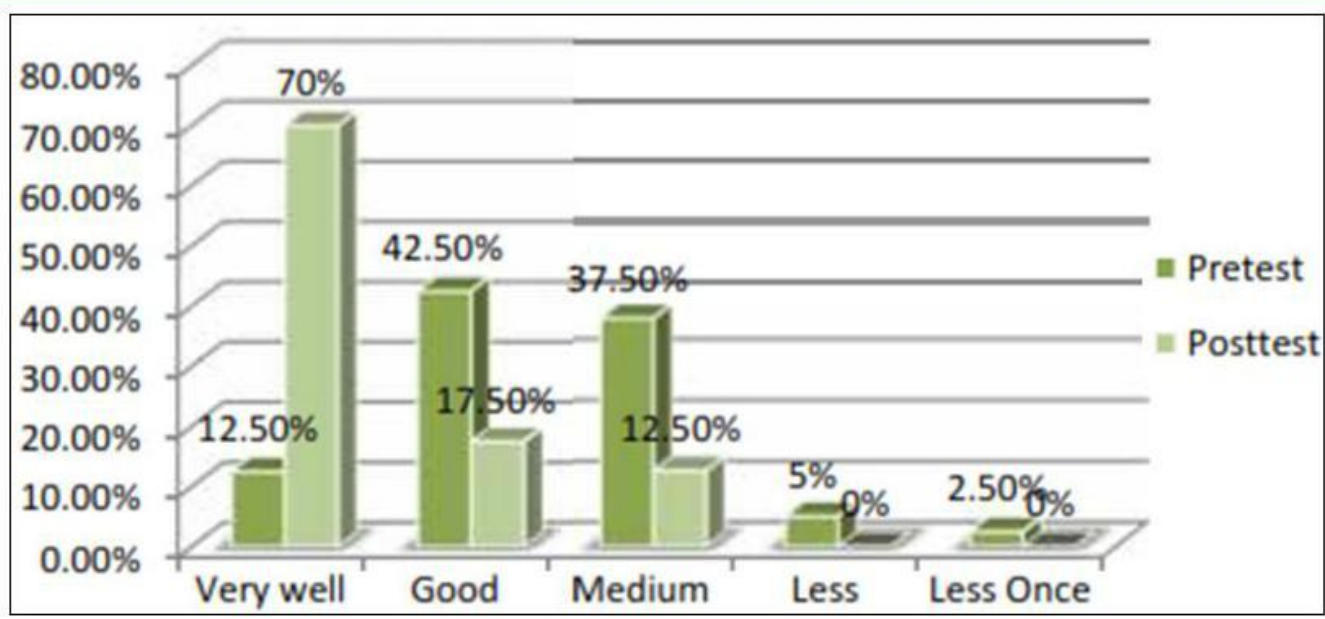

Graph of Category Test Result Basic Techniques Forehand Student Department FIK UNIMED

2) Conventional Forehand Technical Technique Test Results.

\begin{tabular}{|c|c|c|c|c|c|c|}
\hline No & $\begin{array}{c}\text { Test } \\
\text { Results }\end{array}$ & Category & Students & Percentage & Total & Percentage \\
\hline \multirow{5}{*}{1.} & \multirow{5}{*}{ Pretest } & Very well & 6 & $15 \%$ & 6 & $15 \%$ \\
\hline & & Good & 9 & $22,5 \%$ & 9 & $22,5 \%$ \\
\hline & & Medium & 24 & $60 \%$ & 24 & $60 \%$ \\
\hline & & Less & 1 & $2,5 \%$ & 1 & $2,5 \%$ \\
\hline & & $\begin{array}{l}\text { Less } \\
\text { Once }\end{array}$ & 0 & $0 \%$ & 0 & $0 \%$ \\
\hline \multirow{5}{*}{2.} & \multirow{5}{*}{ Posttest } & Very well & 14 & $35 \%$ & 14 & $35 \%$ \\
\hline & & Good & 15 & $37.5 \%$ & 15 & $37,5 \%$ \\
\hline & & Medium & 11 & $27.5 \%$ & 11 & $72,5 \%$ \\
\hline & & Less & 0 & $0 \%$ & 0 & $0 \%$ \\
\hline & & $\begin{array}{l}\text { Less } \\
\text { Once }\end{array}$ & 0 & $0 \%$ & 0 & $0 \%$ \\
\hline
\end{tabular}

From the table above it can be seen that there were 14 students $(35 \%)$ increase in the number of students who fall into the category of forehand basic techniques "very good", from the previous 6 students $(15 \%)$ included in the category "very good". After the exercises were conducted using the conventional tennis forehand conventional exercise model, 8 students (20\%) increased with the basic forehand technique category "very good". In addition, in the category of basic techniques forehand "good" an increase from the previous 9 students $(22.5 \%)$ then after the exercise using conventional tennis forehand conventional techniques to 15 students $(37.5 \%)$ then 6 students $(15 \%)$ Which increase with the basic forehand technique category in the "good" category. Furthermore, in the basic forehand technique category "moderate" there was a significant decrease from the previous 24 students $(60 \%)$ then after the exercise using the basic technique of forehand tennis conventional to 11 students $(27.5 \%)$ on the "medium" category. Thus, 13 students $(32.5 \%)$ decreased in the "moderate" category.

And then there were no more students who fall into the category of forehand basic "less" and "very less" techniques than the previous basic forehand technique category "less" there is 1 student, and forehand basic engineering category "very less" there was 0 student. The result of comparison of the basic forehand technique test before and after the exercise was done by using the Basic Technique Model of
Tennis Conventional On Student can be seen in the following graph.

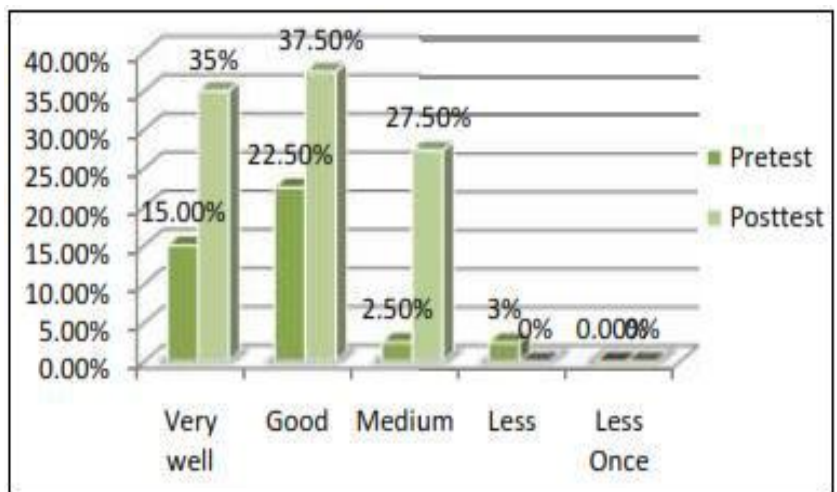

Graph of Category Test Result Basic Techniques Conventional Forehand of FIK UNIMED Students

3) Test of Different Samples (Independent Samples Test) Different mean test of difference between groups to know the difference of treatment effect on the increase of dependent variable of basic tennis forehand exercise technique on student with play approach before and after treatment between groups using Independent Samples Test Statistic from calculation of IBM SPSS21.0 for Windows

\begin{tabular}{|c|c|c|c|c|}
\hline Forehand & Df & $\begin{array}{c}\text { Mean } \\
\text { Difference }\end{array}$ & $\boldsymbol{F}$ & Sig. \\
\hline $\begin{array}{c}\text { Equal } \\
\text { variances } \\
\text { assumed }\end{array}$ & 76 & 5.100 & 7,728 &, 007 \\
\hline
\end{tabular}

Based on the table above it can be concluded that obtained sig value Equal variances assumed (2-tailled) $0.007<0.05$ it can be concluded there were differences in the effect of basic forehand technique and conventional technique training on the basic forehand technique skills in FIK UNIMED students.

\section{Conclusion}

Based on the result of research and discussion it can be concluded as follows;

Volume 6 Issue 7, July 2017 www.ijsr.net 


\section{International Journal of Science and Research (IJSR) \\ ISSN (Online): 2319-7064}

Index Copernicus Value (2015): 78.96 | Impact Factor (2015): 6.391

a) The development research resulted in a product of the basic exercise model of forehand field tennis on the students With a play approach that relates to the basic skills techniques among which were; 7 forms of Basic Forehand technique model with approach to play on FIK UNIMED students.

b) The Forehand Basic Engineering Exercise Model is a model that contains various forms of Forehand practice, which are related to playing approaches that can be used on students especially for students who are new to the tennis sport.

c) Based on the validation and test result, the basic tennis practice products produced by Forehand tennis court with the approach to play on the students as a whole is worth doing for the process of basic tennis technique training on the students. It was based on the results of the analysis of model trial product test. The product of this development model was made in the form of a guidebook as a reference for lecturers and students in the delivery of materials as well as the implementation of basic tennis technique exercises related to the play approach.

d) From the effectiveness test model, it can proved that the product model in the form of basic exercises techniques Forehand tennis on students was high effectiveness. Based on the results of the basic tennis technique test using Hewitt test shows that the average value of post test result was greater than pre-test result. Thus, it was stated that the basic technique model of Forehand tennis for student was effective to use in improving the basic tennis practice result.

\section{References}

[1] Docket, Sue \& Fleer Marlyn. Play \& Pedagogy in Early Childhood - Bending the Rules. (Sidney: Harcourt), 2000.

[2] Jones C.M. \& Angela Buxton, Belajar Tenis lapangan Tenis lapangan untuk Pemula, (Bandung: Pionir Jaya, 2006.

[3] Lumintuarso Ria. Sports Coaching Theory. Jakarta: Lankor, 2013.

[4] Martens, Rainer. Successful Coaching. America, Human Kinetics 2004.

[5] Rusdianto \& Setyo Bidiwanto. The Basics of Sports Qualitative, and $R \& D$ approaches (Bandung: Alfabeta, 2010).

[6] Sukadiyantodan Dangsina, Introduction to Theory and Methodology of Physical Training (Bandung: Lubuk Agung, 2011).

[7] Tangkudung, J danPuspitorini W. Sports Coaching "Sports Performance Coaching", Jakarta: Cerdas Jaya, 2012.

[8] Thompson, P. J. L.. Introduction To Coaching Theory. (Monaco. IAAF). 1994.

[9] Tudor, Bompa, G Gregory Haff, Periodization Theory And Metodolgy Of Training 2009.

[10] Yudoprasetio B. Learning Tennis, The Three Stroke Game (Jakarta: Bhratara Karya Aksara, 1981).

[11]Zulkifli L. Developmental psychology. (Bandung: PT. Remaja Rosdakarya), 2005

Volume 6 Issue 7, July 2017

www.ijsr.net 